\title{
INTERMODAL COMPETITION WITH HIGH SPEED RAIL- A GAME THEORY APPROACH
}

Oliver Feng-Yeu Shyr

Department of Urban Planning, National Cheng Kung University, Tainan 701, Taiwan, R.O.C, ofshyr@mail.ncku.edu.tw

Meng-Fu Hung

Department of Transportation Management, Tamkang University, Taipei 251, Taiwan, R.O.C

Follow this and additional works at: https://jmstt.ntou.edu.tw/journal

Part of the Business Commons

\section{Recommended Citation}

Shyr, Oliver Feng-Yeu and Hung, Meng-Fu (2010) "INTERMODAL COMPETITION WITH HIGH SPEED RAIL- A GAME THEORY APPROACH," Journal of Marine Science and Technology. Vol. 18: Iss. 1, Article 4.

DOI: 10.51400/2709-6998.1862

Available at: https://jmstt.ntou.edu.tw/journal/vol18/iss1/4

This Research Article is brought to you for free and open access by Journal of Marine Science and Technology. It has been accepted for inclusion in Journal of Marine Science and Technology by an authorized editor of Journal of Marine Science and Technology. 


\title{
INTERMODAL COMPETITION WITH HIGH SPEED RAIL- A GAME THEORY APPROACH
}

\author{
Oliver Feng-Yeu Shyr* and Meng-Fu Hung**
}

Key words: high speed rail, coalition, Nash equilibrium, cooperative game.

\begin{abstract}
It was estimated that approximately $50 \%$ of the air trips, $20 \%$ of rail trips, and $15 \%$ of freeway bus trips in Taiwan's western corridor would be replaced by Taiwan High Speed Rail (THSR) [5]. If the carriers of these trips are to compete with THSR, reducing flight frequency and allying airlines might be the most effective approaches. In this paper we calibrate the payoff functions of various modes with stated preference (SP) and revealed preference (RP) data and solve the new Nash Equilibrium by maximizing payoff functions with respect to fare rates and flight frequency after the operation of THSR. In the case study, we predict that allied airlines flying between Taipei and Kaohsiung would be difficult to remain profitable during the first quarter of THSR's operations, but the market share and the daily flight frequency will reduce by more than $50 \%$.
\end{abstract}

\section{BACKGROUND}

After the Inauguration on January 5, 2007, Taiwan High Speed Rail (THSR) began to operate between Banciao Station of Taipei and Kaohsiung at the promotion rate 730 New Taiwan Dollar (NTD) with 17 daily trains each bound. During the three-week promotion period, competitors such as domestic airlines, freeway buses, and Taiwan Railway (TR) were forced to reduce either their fare rates or frequency to prevent further deterioration of profitability. For example, some domestic airlines offered $32 \%$ off discount for weekend travelers to compete with THSR. Starting from March 31, THSR provides 23 daily trains between Taipei and Kaohsiung at full rate 1490 NTD. Up to mid-March, Taiwan's Council for Economic Planning and Development estimated that the average daily passengers of THSR were 33,161. Meanwhile, airlines flying

Paper submitted 06/24/08; revised 10/06/08; accepted 01/12/09. Author for correspondence: Oliver Feng-Yeu Shyr (e-mail: ofshyr@mail.ncku.edu.tw). *Department of Urban Planning, National Cheng Kung University, Tainan 701, Taiwan, R.O.C.

**Department of Transportation Management, Tamkang University, Taipei 251, Taiwan, R.O.C. the same domestic routes dropped more than $10 \%$ of their load factors. For domestic airlines to survive, a unified alliance is needed to rescheduling the daily flight frequency and allocating the profits among them. Similarly, Button [2] suggested that appropriate policy reactions, e.g., removal of some restrictions on airline merging and coalitions, might allow a more sustainable market structure.

In fact, Taiwan's Fair Trade Commission has approved all four airlines flying between Taipei and Kaohsiung to form coalition at the end of the second quarter in 2007 with one restriction, i.e., the daily flights provided by these airlines should not be reduced from the date of their application. As THSR schedules to increase their service frequency in the third and the fourth quarters consecutively, domestic airline found it very difficult to comply with the restrictions. As a result, the coalition fell apart in the fourth quarter and one of the airlines, i.e., Far Eastern Air Transport, had terminated their service in the second quarter of 2008. The development is also consistent with the study by Shyr and Kuo [10] who pointed out that a successful airline coalition would rely on both profitability and financial stability.

A newly published report by Taiwan's Ministry of Transportation and Communications [6] shows the before-and-after comparison of modal splits on Taiwan's western corridor regarding THSR's operations. Based on a survey sample of 1713 passengers, the modal splits before THSR's operations are $29.4 \%$ by TR, $29.1 \%$ by automobiles, $18.6 \%$ by freeway buses, $13.5 \%$ by air, $5.2 \%$ by tour buses, $0.4 \%$ by taxi, $0.2 \%$ by the others, and $3.6 \%$ not reporting any previous modes of transport - these respondents possibly represent new derived demand. After the operation of THSR, the modal splits become $41.9 \%$ by THSR, $14.2 \%$ by TR, $21.4 \%$ by automobiles, $12.8 \%$ by freeway buses, $3.2 \%$ by air, $4.2 \%$ by tour buses, $0.2 \%$ by taxi, and $2.1 \%$ by the others. The report further points out that $67.2 \%$ of 231 previous air passengers would change their mode of travel to THSR while only $20.1 \%$ of them remain unchanged. On the other hand, the splits of the changed/unchanged ratios are $47.6 \%$ and $38.8 \%$ for 503 previous TR travelers, and $32.5 \%$ and $55.2 \%$ for 319 previous freeway bus travelers. In addition, 155 previous air travelers who change their mode of transport to THSR are asked whether they would switch back to air travel if airlines offer cheaper promotion airfares. Only $41.8 \%$ of them reply yes, $17.3 \%$ of them are uncertain, and $40.9 \%$ of them say no. All in 
all, major modes of intercity transport are significantly affected by THSR. But air travel market suffers the most severe damage resulting from THSR's operations. Up to this date, only a handful of weekly flights remain in service on the western corridor. The reasons for airline's dropout of the market are threefold: 1) airlines are forced to cut down most of their services due to soaring gasoline prices in the first half of 2008; 2) THSR continues to increase their frequency while promoting their lower fare rates; and most importantly, 3) airline's chances to reopen the market have been diminished in the short run due to the worldwide economical recession occurred in the second half of 2008.

It is arguable to state that most of the modes of intercity transport, especially airlines, do not act swiftly enough to cope with the change of the market. It is however never too late to set up proper strategies to compete with THSR. Moreover, we should always bear in mind that regulation on price and service frequency of public transportation systems as imposed by the authority is used to be set according to the operational costs under market equilibrium. But the introduction of high speed rail has broken the equilibrium and the operating costs calculated based on historical load factors and existing schedule could no longer be trustworthy under various competition scenarios. And that is why we propose new price regulations under new service frequency based on social welfare which could be justified by the greater good of our society. In this paper we focus on three issues regarding strategic planning: what are the new rules of the market? In other words, what are the new price regulations and new service frequency under the impacts of THSR on all competing modes? What should the competing modes, especially airlines and freeway buses, react with coalition strategies regarding pricing and operation planning? And how to allocate profits among allied members? To begin with our analysis, we first formulate the modal choice model and the payoff functions for all competing modes. Next, we solve Nash equilibrium among competing modes and use cooperative games methods to allocate profits among airlines. A case study based on data collected from the biggest domestic air travel OD market, i.e., Taipei-Kaohsiung, is given to assess the consequences after the operation of THSR. In the case study, we assume that THSR is the leader of the market - according to the new market shares published by the authority; while airlines and freeway buses are the followers of the market. We do not propose scheduling strategies for railway and assume its service frequency remains unchanged because we do not have any information regarding its operating costs and we also acknowledge that railway scheduling is set by Taiwan Railway Administration (TRA), whose objective is to provide reliable yet not necessary profitable services for both urban commuters and intercity travelers. Meanwhile, there are many types of coalitions among transport carriers. For example, airlines could form alliances through merging or stock exchange, parallel or complementary code-sharing. Because our case study is built upon Taiwan's domestic market, we would be focused on parallel code-sharing as the form of airline coalitions.

\section{MODEL FORMULATION}

To model the competition among various airlines under hub-and-spoke network, Hansen [4] had done one of the pioneer works to apply non-cooperative game approach to solve the optimal airfares and flight frequency for airlines. Since then, airline preferred to form alliances, i.e., to play cooperative games, to enhance market shares and to reduce costs. As a result, we adopt cooperative game methods to deal with airline coalitions. On the other hand, domestic transport carriers still play non-cooperative game in the market competition. To analyze modal competition, we apply the concept of Nash equilibrium to deal with the profit maximization problem using decision variables such as fare rates and frequency for all competitors. As for cooperative games, we adopt Shapley value as our solution approach. The solution concept of Shapley value is to allocate profits based on the proportions of contributions derived from all allied members. Unlike other cooperative game approaches, Shapley value almost guarantees to have solutions if we add some appropriate assumptions. To begin with our analysis, we adopt the following assumptions based on the nature of the market:

1) All coalitions satisfy the super-additive property;

2) All competitors have perfect information regarding costs and revenues of the others,

3) Fare rates of all competitors are subject to upper-bound constraints designed to maximize social welfare;

4) All competitors are looking for profit maximization under the pricing constraints of upper-bound fare rates,

5) All competitors, except railways, would reschedule their headways according to their design load factors.

The first assumption means that the total payoffs for any coalition should always increase if a new player joins the coalition. This assumption is reasonable if the action of alliance reduces average costs and increases market shares. The second assumption states the fact that information regarding costs and demands is often well known in transportation industry. The third and the fourth assumes that in the short run, the objective of each competitor is to look for the best strategy that yields the maximum profits under pricing restrictions. The last assumption addresses the need for rescheduling if actual load factors considerably exceed or fall below the design load factors, which are estimated percentiles based upon the average operating costs and fare rates. And the reason for the exclusion of railway has been stated in the background section. These pricing restrictions are set to maximize social welfare by the transportation authority. Table 1 is the list of all sets, functions, variables, parameters, and their descriptions. 
Table 1. List of sets, functions, variables, and parameters.

\begin{tabular}{|c|c|}
\hline Symb & Description \\
\hline \multicolumn{2}{|c|}{ Sets/Subsets } \\
\hline$A$ & The set of all transport carriers of an O-D pair \\
\hline$A_{d}$ & The set of all transport carriers in cluster $d$ \\
\hline$A_{d m}$ & The set of all carriers of mode $m$ in cluster $d$ \\
\hline$D$ & The set of all clusters in the market \\
\hline$M$ & The set of all modes \\
\hline$N$ & The set of all players in the cooperative game \\
\hline$S$ & The subset of players in the cooperative game \\
\hline \multicolumn{2}{|c|}{ Functions } \\
\hline CS & The consumer surplus of the transport market \\
\hline$Q$ & The travel demand in the market \\
\hline$q$ & The predicted daily revenue passengers \\
\hline$R$ & The market share of a transport carrier \\
\hline Round & The function of rounded integers \\
\hline$S W$ & The social welfare of the transport market \\
\hline$V$ & The utility function of a transport carrier \\
\hline$L$ & The natural log value of the objective function \\
\hline$\pi$ & The payoff function of a transport carrier \\
\hline \multicolumn{2}{|c|}{ Variables (in Vectors or Matrices) } \\
\hline$F$ & The daily service frequency \\
\hline $\mathbf{P}, \overline{\mathbf{P}}$ & The vectors of fare rates and their upper bounds \\
\hline $\mathbf{P}_{\mathbf{0}}$ & The vector of initial fare rates \\
\hline$P, \bar{P}$ & The fare rate and its upper bound \\
\hline$s$ & The slack variables in the pricing constraints \\
\hline $\mathbf{Z}$ & The matrix of other attributes of utility function \\
\hline \multicolumn{2}{|c|}{ Parameters/Labels (in Vector or Matrix) } \\
\hline$a$ & The average direct operating costs per flight/bus \\
\hline$b$ & The average service cost per passenger \\
\hline$c$ & The average daily operating costs per passenger \\
\hline$D O C$ & The average daily operating costs \\
\hline$d$ & The label of a cluster with related modes \\
\hline$k$ & The label for a transport carrier \\
\hline$\hat{L}$ & The design load factor \\
\hline$m$ & The label of a transport mode \\
\hline Seat & The average number of seats per flight/bus \\
\hline$W P$ & The maximal willingness to pay by passengers \\
\hline$\alpha$ & $\begin{array}{l}\text { The vector of parameters for other attributes in the } \\
\text { utility function }\end{array}$ \\
\hline$\beta$ & The parameter of fare rate in the utility function \\
\hline
\end{tabular}

\section{Market Shares and Predicted Daily Revenue Passengers of all Competitors}

Instead of applying aggregate models, we adopt the discrete choice model to estimate the payoffs of all competitors based on two reasons: 1) the stated preference (SP) data which contain passenger's preferences on choices of future trips with the inclusion of a new mode are valuable to assess the behavior of travelers; 2) the model has an advantage of combining both the revealed preference (RP) data and the SP data. The RP data refer to the choices of carriers without the new mode.
To calibrate model parameters, it is necessary to combine both SP and RP data using combined estimation techniques derived by Morikawa [7] because SP data often lead to significant estimation of model parameters while RP data are more reliable for interpretation of consumer behavior. Our model calibration is completed in two steps: 1 ) the market demand for an O-D pair, $Q$, is calibrated by using historical demand data with exogenous socio-economic variables, i.e., economic growth rate, GDP, etc; 2 ) the market share model, formulated as a nested multinomial model as shown in (1) to (6), is calibrated by using SP and RP data. Equations (1) through (3) represent the utility function of a transport carrier in the nested structure. Attributes other than fare rates in these equations include headway, travel time, and the service quality of each transport carrier.

Equations (4) through (6) formulate the market shares which are calibrated as a nested multinomial Logit (NMNL) model, a modified version of the multinomial Logit (MNL) model developed by Ben-Akiva and Lerman [1]. The choice between MNL and NMNL is determined by the Independent of Irrelevant Alternatives Test (IIA Test). If the IIA test failed, a NMNL model would replace a MNL model. The structure of our nested Logit consists of three levels: the upper level includes the clusters of highly correlated modes, the middle level consists of the modes of these clusters, and the lower level includes the carriers of the same mode. The travel demand of transport carrier $k$ is formulated as a product of OD demand and market share as shown in (7). The relationship among the sets of carriers is shown in (8). All these sets in (8) are mutually exclusive.

$$
\begin{gathered}
V_{d m k}=\mathbf{Z}_{d m k} \boldsymbol{\alpha}_{d m}+\beta_{d m} P_{d m k} \\
V_{d m}=\mathbf{Z}_{d m} \boldsymbol{\alpha}_{d}+\gamma_{d} \ln \sum_{k \in A_{d m}} V_{d m k} \\
V_{d}=\mathbf{Z}_{d} \boldsymbol{\alpha}+\gamma \ln \sum_{m=1}^{M_{d}} V_{d m} \\
R_{d m k}=R_{d m} \times e^{V_{d m k}} \sum_{k=1}^{K_{d m}} e^{V_{d m k}} \\
R_{d m}=R_{d} \times e^{V_{d m}} \sum_{m=1}^{M_{d}} e^{V_{d m}} \\
R_{d}=e^{V_{d}} / \sum_{d=1}^{D} e^{V_{d}} \\
q_{d m k}=Q \times R_{d m k}
\end{gathered}
$$




$$
A=\bigcup_{d=1}^{D} A_{d}, \quad A_{d}=\bigcup_{m=1}^{M_{d}} A_{d m}
$$

\section{Cost Functions of all Competitors}

The daily operating cost of a transport carrier formulated as (9) includes the indirect cost, namely the passenger service cost, and the direct operation costs which consist of fuel cost, labor cost, maintenance cost, salvage cost, airport cost, and capital cost. For scheduling purpose, the frequency in (9) could be rewritten as (10) to estimate the required number of daily service frequency. According to previous empirical experience, the design load factors often lie between $60 \%$ and $70 \%$ for domestic airlines, $70 \% \sim 80 \%$ for freeway and bus. As for railway, there is no design load factor to be used in the study because the scheduling of railway operations is usually unrestricted by design load factor.

$$
\begin{gathered}
D O C_{d m k}=a_{d m k} \times F_{d m k}+b_{d m k} \times q_{d m k} \\
F_{d m k}=\text { Round }\left[q_{d m k} / S_{\text {Seat }} \times \hat{L}_{d m k}\right]
\end{gathered}
$$

\section{Payoff Functions of all Competitors}

By the substitution of (7), (9) and (10), we formulated the payoff function as shown in (11) which consists of the estimated daily profits and the daily operation costs associated with the carrier $k$. If the daily frequency exceed 20 or the weekly flights are over 100, then for scheduling purpose, Eq. (11) could be approximated as (12) with a relatively small margin of error.

$$
\begin{gathered}
\pi_{d m k}=\left(P_{d m k}-b_{d m k}\right) \times Q \times R_{d m k}-a_{d m k} \\
\times \text { Round }\left[\frac{Q \times R_{d m k}}{\text { Seat }_{d m k} \times \widehat{L}_{d m k}}\right] \\
\pi_{d m k} \cong\left(P_{d m k}-b_{d m k}-\frac{a_{d m k}}{S e a t_{d m k} \times \widehat{L}_{d m k}}\right) \times Q \times R_{d m k} \\
=\left(P_{d m k}-c_{d m k}\right) \times Q \times R_{d m k}
\end{gathered}
$$

\section{SOLUTION APPROACH}

The solution approach consists of four steps: 1) calibrating market share models; 2) estimating payoffs for various carriers; and 3) solving optimal fare rates and daily service frequency under Nash equilibrium; and 4) solving profit distribution problem by using Shapley values.

\section{Model Calibration}

The calibration begins with the questionnaire survey on travelers' preference on choices of transport carriers under various competition scenarios. The survey is conducted by general stratified sampling, i.e., the sample should be drawn in proportion to the market shares. Calibration procedures for deriving these load factors are as follows: 1) calibrating the average load factor for transport carrier $k$ of mode $m$ from O-D pair $(i, j)$ by using historical load factor data, and estimating the total daily revenue passengers for this O-D pair as shown in Eq. (1); and 2) calibrating the market shares for all carriers by using the combined estimation of RP and SP data. The market share model includes all the attributes related to the quality of services and fare rates. The functional form of the utility function is usually assumed to be linear. In addition, alternative-specific constants are often specified in the utility function to reveal qualitative characteristics of the services provided by the carriers.

\section{Solution Approach of Nash Equilibrium}

The solution of Nash Equilibrium is adopted from the study by Shyr and Kuo [10] and derived from the following procedures: 1) finding the upper bound fare rates that satisfy maximum social welfare shown in (13); and 2) solving the system of maximization problems for all competitors as shown in (14). Equation (13) is the formulation defined by the third assumption while (14) is defined by the fourth assumption.

$$
\begin{gathered}
\max _{\overline{\mathbf{P}}} \sum_{d=1}^{D} \sum_{m=1}^{M_{d}} \sum_{k \in A_{d m}} \pi_{d m k}(\overline{\mathbf{P}})+C S_{d m k}(\overline{\mathbf{P}}), \\
C S_{d m k}(\overline{\mathbf{P}})=\int_{\bar{P}_{d m k}}^{W P_{d m k}} q_{d m k}(\mathbf{P}) d P_{d m k} \\
\text { Subject to } \bar{P}_{d m k} \geq 0, \forall k, \forall m, \forall d \\
\max _{\mathbf{P}} \pi_{d m k}(\mathbf{P}), \text { subject to } 0 \leq P_{d m k} \leq \bar{P}_{d m k}, \forall k, \forall m, \forall d
\end{gathered}
$$

Both (13) and (14) require techniques of non-linear optimization and their first order conditions, as shown in (15) and (16), may have multiple solutions.

$$
\frac{\partial}{\partial \bar{P}_{d m k}} \sum_{d=1}^{D} \sum_{m=1}^{M_{d}} \sum_{k \in A_{d m}}\left[\pi_{d m k}(\overline{\mathbf{P}})+C S_{d m k}(\overline{\mathbf{P}})\right]=0, \forall k, \forall m, \forall d
$$

$\frac{\partial \pi_{d m k}}{\partial P_{d m k}}=0, P_{d m k}+s_{d m k}=\bar{P}_{d m k}, s_{d m k} \geq 0, \forall k, \forall m, \forall d$

However, empirical study by Shyr and Chang [9] suggested that the profit functions shown in (13) and (14) have unique solutions, as shown in Appendix. In addition, the functional form of consumer's surplus (CS) is quite similar to the form of profit functions, i.e., a logistic-form demand function multi- 
plied by airfare. As a result, we assume that CS would have unique solution as well. Next, we solve (15) by applying functions to solve system of nonlinear equations in MATHEMATICA [12]. And finally, we apply the same approach to solve (16) and check if our solutions are bounded with the upper-bound constraints. It is often the case that the optimal fare rates solved by (16) are bounded by upper-bounds solved by (15). This is because the optimal solution $P_{a}^{*}$ of CS would not be higher than the optimal solution $P_{c}^{*}$ of supplier's profits $\pi$ due to the fact that the lower the optimal prices, the higher the CS; on the contrary, the higher the optimal prices, the higher the $\pi$. As a result, the optimal solution $P_{b}^{*}$ of $\pi+$ $\mathrm{CS}$, as shown in Fig. 1, would be lower than $P_{c}^{*}$. In summary, we have the relationship of these optimal solutions as $P_{a}^{*} \leq P_{b}^{*} \leq P_{c}^{*}$.

Another alternative to solve (13) and (14) is to apply the first order Taylor series to the predicted daily revenuepassengers $q$ as shown in (17) such that the objective functions in (13) and (14) can be approximated as quadratic functions of fare rates and (15) and (16) can be transformed into systems of linear equations. In the case study, we use the fare rates in 2006 for all competing carriers as the vector of $\mathbf{P}_{0}$ applied to (17).

$$
q_{d m k}(\mathbf{P}) \cong q_{d m k}\left(\mathbf{P}_{0}\right)+\left.\left(\mathbf{P}-\mathbf{P}_{0}\right)^{\prime} \frac{\partial q_{d m k}(\mathbf{P})}{\partial \mathbf{P}}\right|_{\mathbf{P}=\mathbf{P}_{0}}
$$

\section{Solution Approach of Cooperative Games}

To evaluate the contributions of allied members in the cooperative games, we propose the following procedures based on the concept described by Owen [8] and Curiel [3].

\section{Step 1: List all coalition structures.}

A coalition structure is defined as a partition of all players in the cooperative game. For example, if five airlines are forming various alliances, their coalition structures will be $S=$ $\{1\}$ versus $N-S=\{2,3,4,5\}, S=\{3,4\}$ versus $N-S=\{1,2,5\}$, etc. As a result, there will be $2^{N-1}$ coalition structures.

\section{Step 2: Calibrate the payoff functions of all coalition struc- tures.}

The payoff functions are calibrated by using the same model as in the non-cooperative game, but the data is collected from travelers' stated preference regarding their new choices of carriers if new alliances among airlines were developed.

\section{Step 3: Solve the market equilibrium under all coalition structures.}

Based on the assumption of efficiency, i.e., if a coalition $S$ were formed, then the others would be forced to form another coalition $N-S$ to compete with it, a solution of the following

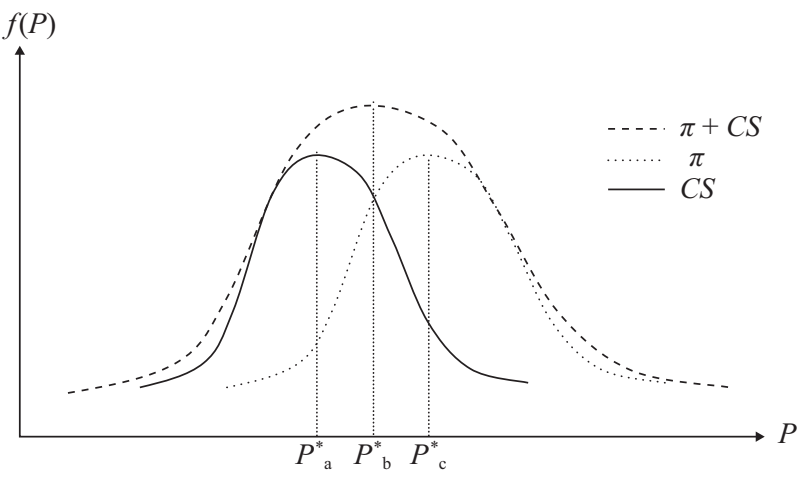

Fig. 1. Optimal Solutions to CS, $\pi+\mathrm{CS}$, and $\pi$, respectively.

systems of equations yields the maximum profit and the optimal fare rates to each coalition structure under market equilibrium, as shown in (18). The same approach was also adopted by Shyr and Kuo [10].

$$
\left\{\begin{array}{c}
\frac{\partial \pi_{S}}{\partial F_{S}}=0 \\
\frac{\partial \pi_{N-S}}{\partial F_{N-S}}=0
\end{array}\right\} \quad \forall S \subset N
$$

Similarly, Eq. (18) could be solved by the technique of Taylor series approximation.

\section{Step 4: Apply software MATHEMATICA to solve the Shapley value.}

Given the payoffs derived from Step 3, we could apply MATHEMATICA to compute the Shapley value and solve the profit distribution problem in the case study.

\section{CASE STUDY}

Our case study is based on the survey data collected from the travelers between Taipei and Kaohsiung in 2005. The players of the game include five modes, i.e., automobiles, THSR, TR, freeway buses, and airlines. The surveys were conducted at the boarding lounges at Taipei airport, the Taipei Station of Taiwan Railway and Freeway Buses, and the major service areas along the Freeways. We assume freeway buses also form coalitions in competition with THSR, but we do not analyze their coalitions in the paper. A study by Shyr and Shieh [11] adopts the same approach to analyze coalitions of freeway buses in their case study for the Taipei-Taichung intercity travel market.

\section{Model Calibration Results}

Table 2 shows the calibration results for the market share model with the combination of SP and RP data as a nested Logit model. In Table 2, Constant IV means the logarithm of the sum of utility function within the same cluster. Since the 
Table 2. Calibrated parameters of the nested modal choice models ( $t$ values in parentheses).

\begin{tabular}{|c|c|c|c|c|}
\hline \multirow{2}{*}{ Variables } & \multirow[b]{2}{*}{$\begin{array}{l}\text { Multinomial } \\
\text { Logit }\end{array}$} & \multicolumn{2}{|c|}{ Lower Level } & \multirow[b]{2}{*}{$\begin{array}{l}\text { Upper } \\
\text { Level }\end{array}$} \\
\hline & & $\begin{array}{c}\text { High-Fare } \\
\text { Modes }\end{array}$ & $\begin{array}{c}\text { Low-Fare } \\
\text { Modes }\end{array}$ & \\
\hline $\begin{array}{c}\text { Constant: Air } \\
\text { (RP) }\end{array}$ & $\begin{array}{c}0.043 \\
(1.507)\end{array}$ & $\begin{array}{c}-1.222 \\
(-0.848)\end{array}$ & NA & NA \\
\hline $\begin{array}{l}\text { Constant: Air } \\
\text { (SP) }\end{array}$ & NA & $\begin{array}{c}-1.337 \\
(-1.753)\end{array}$ & NA & NA \\
\hline $\begin{array}{c}\text { Constant: TR } \\
\text { (RP) }\end{array}$ & $\begin{array}{c}0.08 \\
(4.779)\end{array}$ & NA & $\begin{array}{c}1.113 \\
(4.994)\end{array}$ & NA \\
\hline $\begin{array}{l}\text { Constant: TR } \\
\text { (SP) }\end{array}$ & NA & NA & $\begin{array}{c}0.891 \\
(3.395)\end{array}$ & NA \\
\hline $\begin{array}{c}\text { Constant: Bus } \\
\text { (RP) }\end{array}$ & $\begin{array}{c}0.556 \\
(4.758)\end{array}$ & NA & $\begin{array}{c}1.372 \\
(7.188)\end{array}$ & NA \\
\hline $\begin{array}{c}\text { Constant: Bus } \\
\text { (SP) }\end{array}$ & NA & NA & $\begin{array}{l}1.885 \\
(6.925)\end{array}$ & NA \\
\hline $\begin{array}{c}\text { Constant: } \\
\text { Hi-fare }\end{array}$ & NA & NA & NA & $\begin{array}{c}-0.007 \\
(-1.939)\end{array}$ \\
\hline Constant: IV & NA & NA & NA & $\begin{array}{c}0.400 \\
(6.984)\end{array}$ \\
\hline $\begin{array}{c}\text { Fare Rate } \\
\text { (1000 NTD) }\end{array}$ & $\begin{array}{c}-0.253 \\
(-0.396)\end{array}$ & $\begin{array}{c}-0.54 \\
(-0.644)\end{array}$ & $\begin{array}{c}-1.45 \\
(-4.823)\end{array}$ & NA \\
\hline $\begin{array}{l}\text { Headway } \\
\text { (10 min.) }\end{array}$ & $\begin{array}{c}-0.118 \\
(-5.379)\end{array}$ & $\begin{array}{l}-0.3651 \\
(-5.030)\end{array}$ & $\begin{array}{c}-0.226 \\
(-6.311)\end{array}$ & NA \\
\hline $\begin{array}{l}\text { Travel Time } \\
\text { (100 min.) }\end{array}$ & $\begin{array}{c}-0.507 \\
(-2.150)\end{array}$ & $\begin{array}{c}-0.176 \\
(-0.805)\end{array}$ & $\begin{array}{c}-0.103 \\
(-4.217)\end{array}$ & NA \\
\hline$L(\beta)$ & -539.56 & -365.68 & -758.5 & -1035.1 \\
\hline$L(0)$ & -606.34 & -547.59 & -814.07 & -1261.2 \\
\hline$\rho^{2}$ & 0.110 & 0.33 & 0.06 & 0.18 \\
\hline $\begin{array}{l}\% \text { Correct } \\
\text { Prediction }\end{array}$ & 52.083 & $77 \%$ & $53 \%$ & $59 \%$ \\
\hline No. of Sample & 384 & 790 & 741 & 1531 \\
\hline
\end{tabular}

parameter of the constant rejects the null hypothesis $\mathrm{H}_{0}$ : $\beta_{\mathrm{IV}}=$ 1 , we could conclude that the NMNL would be a better specification than MNL. Based on the IIA tests and model specification tests, our study suggest that the best nested structures would be airlines and THSR in the "high-fare" cluster with freeway buses, TR, and automobiles in the "low-fare" cluster. The signs of the estimated parameters for fare rate, frequency, and travel time are all negative, which is consistent with the fact that lower utility often resulted from higher fare rates, longer headways or travel time. The alternative-specific constants shown in Table 2 indicate that passengers would prefer to travel by THSR rather than by airlines. In addition, freeway buses and railway are more favorable alternatives than driving private cars. The results are consistent with the fact that
Table 3. Model validation of the revealed preference data.

\begin{tabular}{|c|c|c|c|c|c|}
\hline \multirow{2}{*}{ Mode } & \multicolumn{2}{|c|}{ Market Share } & \multicolumn{2}{|c|}{ Sample } & \multirow{2}{*}{ Chi-Square } \\
\hline & Observed & Predicted & Observed & Predicted & \\
\hline Air & $37.9 \%$ & $37.2 \%$ & 145 & 142 & 0.061 \\
\hline TR & $12.0 \%$ & $14.9 \%$ & 46 & 57 & 2.840 \\
\hline Bus & $29.0 \%$ & $28.0 \%$ & 111 & 107 & 0.108 \\
\hline Auto & $21.1 \%$ & $19.8 \%$ & 81 & 76 & 0.308 \\
\hline Total & $100.0 \%$ & $100.0 \%$ & 383 & 383 & 3.316 \\
\hline
\end{tabular}

Note: the critical value of the chi-square test at $95 \%$ confident level is 7.815 .

Table 4. Estimated operation costs of the Taipei-Kaohsiung air travel market (in NTD).

\begin{tabular}{c|ccccccc}
\hline & & & & 2004 & 2006 & $\begin{array}{c}\text { Average } \\
\text { Operation }\end{array}$ & $\begin{array}{c}\text { Average } \\
\text { Airline }\end{array}$ \\
& $\begin{array}{c}\text { Types of } \\
\text { Aircraft }\end{array}$ & $\begin{array}{c}\text { Seats/ } \\
\text { Flight }\end{array}$ & $\begin{array}{c}\text { Daily } \\
\text { Flights }\end{array}$ & $\begin{array}{c}\text { Load } \\
\text { Factors }\end{array}$ & $\begin{array}{c}\text { Airfares } \\
\text { (Full-Price) }\end{array}$ & $\begin{array}{c}\text { Costs Per } \\
\text { Costs Per } \\
\text { Flight }\end{array}$ & Passenger \\
\hline \multirow{2}{*}{ FAT } & MD-83 & 172 & 5 & $62.5 \%$ & 2,124 & 230,000 & 2,140 \\
& B757 & 207 & 12 & $62.5 \%$ & & 270,000 & 2,087 \\
TNA & A-321 & 194 & 5 & $54.9 \%$ & 2,020 & 260,000 & 2,441 \\
UNA & MD-90 & 155 & 15 & $62.9 \%$ & 2,122 & 200,000 & 2,051 \\
MDA & B737-800 & 108 & 16 & $73.5 \%$ & 2,109 & 160,000 & 2,016 \\
\hline
\end{tabular}

Note: NTD, New Taiwan Dollar, 1 USD = 32 NTD.

travelers think that taking THSR is much safer than flying. Also, travelers prefer freeway buses and railways, which are considered to be a more comfortable way of travel as it takes about 5 hours to drive from Taipei to Kaohsiung.

Because the cost data are very confidential in the business, we do not have the cost data from Taiwan Railway and THSR. In other words, we have no information regarding the operating cost per train for THSR and TR. As a result, we could only estimate the changes of revenues before and after the operations of THSR based on the current schedules of these two carriers. For airlines and bus, we adopt the data published by the Bureau of Civil Aviation and the data provided by the Union of Freeway Buses to estimate the average daily operation costs per flight and per bus. To verify the market share models, we present Table 3 to show the validation of the model with RP data by a Chi-square test. The results indicate that the differences between the observed and the predicted market shares are insignificant.

Table 4 show the estimated costs per flight for four airlines, i.e., Far Eastern Air Transport (FAT), Trans Asia Airways (TNA), UNI Air ${ }^{\dagger}$ (UNA), and Mandarin Airlines ${ }^{\ddagger}$ (MDA) with the flight distance of 207.5 miles between Taipei and Kaohsiung. From Table 4, we learn that domestic airlines have little room for profitability in the competitive market.

\footnotetext{
${ }^{\dagger}$ The airline was merged by EVA Air in 1995 and was renamed as UNI Air since 1996.

${ }^{\ddagger}$ The airline is wholly owned by China Airlines since 1992 as the other partner pulled out their investment.
} 
Table 5. Service attributes and fare rates of all modes before and after THSR's Operations.

\begin{tabular}{c|cccccc}
\hline Scenario & Headway (min) & $\begin{array}{c}\text { Travel } \\
\text { Time } \\
\text { Modes }\end{array}$ & Before & $\begin{array}{c}\text { Access } \\
\text { Time to } \\
\text { CBD } \\
\text { After }\end{array}$ & $\begin{array}{c}\text { Fare Rate (NTD) } \\
\text { (min) }\end{array}$ & $\begin{array}{c}\text { Price } \\
\text { Bound }\end{array}$ \\
\hline Air & 15 & 30 & 75 & 15 & 2110 & 2250 \\
THSR & NA & 50 & 90 & 15 & 1490 & 1510 \\
TR & 45 & 45 & 270 & 0 & 850 & 850 \\
Bus & 25 & 25 & 300 & 0 & 575 & $610^{*}$ \\
Auto & 0 & 0 & 300 & 0 & 910 & $910^{* *}$ \\
\hline
\end{tabular}

* Our predicted upper bound for bus fare is much higher than 610 NTD. However, bus fares are strictly regulated by the transport authority. As a result, we modify our upper bound to be within $10 \%$ margin.

** The costs of driving which include gasoline cost and freeway tolls are assumed to be shared by two persons.

\section{Solutions of Nash Equilibrium}

To solve the Nash Equilibrium in (14), we need information regarding the upper bound of fare rates. Based on (13), we predict that the reasonable margins between the 2006 fare rates and their pricing upper bounds should be within $10 \%$ as shown in Table 5. The data provided by Table 5 are used to solve the Nash Equilibrium to produce Table 6 which highlights the optimal fare rates, market shares, load factors, payoffs, consumer surplus, and social welfares prior to and after the operations of THSR in the first year. By comparing Table 5 and 6, we find that the optimal fare rates of all carriers are bounded by their upper bound constraints. If these constraints were lifted, the optimal fare rates should be higher than their upper bounds. In other words, the optimal fare rates derived from the profit maximization of all competitors should be higher than the ones derived from the maximization of social welfare.

From Tables 6, we also learn that the operations of THSR may have minor impacts on railway and freeway buses in the first year. On the other hand, airlines would probably lose half of their daily revenue passengers. To maintain profitability, airlines would have to unify as an alliance and cut their daily flights by $50 \%$. In addition, our estimation suggests that if THSR sets its fare at 1510 NTD, airlines and freeway may have room for raising their fare rates by $6 \%$ to increase their revenues. The reason why they are still attractive to travelers even if they raise their fares is that THSR could operate at 19 trains per day in the first year, only one third of the fully capacity in the future, and the fare of THSR is $16 \%$ higher than the rate announced in early 2006. In other words, if THSR do not increase their daily operating frequency soon after the first year of operations, airlines as well as freeway buses may have good chances to remain profitable.
Table 6. Modal comparison (a) - fare rates, market shares, daily passengers, and load factors.

\begin{tabular}{c|cccccc}
\multirow{2}{*}{ Scenario } & \multicolumn{2}{|c}{ Fare Rates } & \multicolumn{2}{c}{ Market Shares } & \multicolumn{2}{c}{ Frequency } \\
\cline { 2 - 7 } Modes & before & after & before & after & before & after \\
\hline Air & 2,110 & 2,250 & $37.1 \%$ & $18.4 \%$ & 53 & 27 \\
THSR & NA & 1,510 & NA & $30.3 \%$ & NA & 23 \\
TR & 850 & 850 & $14.9 \%$ & $13.8 \%$ & 16 & 16 \\
Bus & 575 & 610 & $28.1 \%$ & $29.1 \%$ & 216 & 216 \\
Auto & 910 & 910 & $19.9 \%$ & $8.4 \%$ & NA & NA \\
Total & & & $100 \%$ & $100 \%$ & & \\
\hline
\end{tabular}

Table 6. Modal comparison (b) - daily passengers and load factors.

\begin{tabular}{c|cccc}
\hline \multirow{2}{*}{ Scenario } & \multicolumn{2}{|c}{ Passengers } & \multicolumn{2}{c}{ Load Factors } \\
\cline { 2 - 5 } Modes & before & after & before & after \\
\hline Air & 5357 & 2649 & $64.0 \%$ & $63.6 \%$ \\
THSR & NA & 4367 & NA & $75.9 \%$ \\
TR & 2155 & 1985 & $90.5 \%$ & $83.4 \%$ \\
Bus & 4042 & 4200 & $78.0 \%$ & $81.0 \%$ \\
Auto & 2860 & 1213 & NA & NA \\
Total & 14414 & 14414 & & \\
\hline
\end{tabular}

Table 6. Modal comparison (c) - payoffs, consumer surplus, and social welfares (in \$1,000 NTD).

\begin{tabular}{c|cc|cr|cc}
\hline \multirow{2}{*}{ Scenario } & \multicolumn{2}{|c|}{ Payoffs } & \multicolumn{2}{|l|}{ Consumer Surplus } & \multicolumn{2}{|l}{ Social Welfares } \\
\cline { 2 - 7 } Modes & & & \multicolumn{2}{|l}{} & & \\
before & after & before & after & before & after \\
Air & 51 & 338 & 17,597 & 8,827 & 17,649 & 9,165 \\
THSR & NA & 6,593 & NA & 13,965 & NA & 20,558 \\
TR & 1,831 & 1,686 & 2,003 & 1,859 & 3,834 & 3,545 \\
Bus & $\$ 308$ & $\$ 462$ & 4,038 & 4,090 & 4,347 & 4,552 \\
Auto & NA & NA & NA & NA & NA & NA \\
Total & 2,191 & 9,079 & 23,639 & 28,741 & 25,830 & 37,820 \\
\hline
\end{tabular}

\section{Solutions of Profit Distribution Among Airlines by Cooperative Games}

To evaluate the contribution of all airlines in various coalition scenarios, we present Table 7 to show the coalitional payoffs and the optimal airfares derived from (18). The estimated payoffs are derived from a different set of the SP demand data that contain only the survey of air traveler's choices on various airline coalitions. The data were then used to estimate the market shares and the payoffs of various airline coalitions. From Table 7 we learn that if airline still compete with each other in pricing, they would not be profitable in most cases. In other words, the best strategy would be forming a unified alliance to prevent pricing competition among them so as to increase total revenues for the air travel market. 
Table 7. Airlines' coalitional payoffs and optimal airfares in cooperative games.

\begin{tabular}{|c|c|c|c|c|c|}
\hline $\begin{array}{l}\text { Coalitions } \\
\qquad\left(\mathrm{T}_{\mathrm{i}}\right)\end{array}$ & $\begin{array}{c}\text { Payoffs } \\
\text { (NTD/Day) }\end{array}$ & $\begin{array}{c}\text { Optimal } \\
\text { Airfare } \\
\text { (NTD) }\end{array}$ & $\begin{array}{c}\text { Daily } \\
\text { Revenue } \\
\text { Passengers }\end{array}$ & $\begin{array}{c}\text { Load } \\
\text { Factors }\end{array}$ & Flights/Day \\
\hline FAT, TNA & $-1,877,384$ & 1,473 & 3,247 & 0.7526 & 22 \\
\hline UNA, MDA & $-922,063$ & 1,528 & 3,945 & 0.9733 & 31 \\
\hline FAT, UNA & $-1,530,036$ & 1,440 & 5,264 & 0.9285 & 32 \\
\hline TNA, MDA & $-2,154,362$ & 1,312 & 1,788 & 0.6627 & 21 \\
\hline FAT, MDA & $-1,864,602$ & 1,422 & 4,708 & 0.9283 & 33 \\
\hline TNA, UNA & $-2,419,376$ & 1,236 & 2,128 & 0.6459 & 20 \\
\hline FAT & $-1,710,850$ & 1,196 & 3,051 & 0.9124 & 17 \\
\hline $\begin{array}{c}\text { UNA, TNA, } \\
\text { MDA }\end{array}$ & $-3,303,884$ & 1,719 & 2,877 & 0.5728 & 36 \\
\hline TNA & 152,095 & 1,583 & 917 & 0.9457 & 5 \\
\hline $\begin{array}{c}\text { FAT, UNA, } \\
\text { MDA }\end{array}$ & $-1,125,336$ & 2,021 & 5,534 & 0.7482 & 48 \\
\hline UNA & $-885,408$ & 1,336 & 2,144 & 0.9222 & 15 \\
\hline $\begin{array}{l}\text { TNA, FAT, } \\
\text { MDA }\end{array}$ & $-3,062,364$ & 1,863 & 3,649 & 0.6039 & 38 \\
\hline MDA & $-1,199,697$ & 1,262 & 1,585 & 0.9173 & 16 \\
\hline $\begin{array}{c}\text { TNA, FAT, } \\
\text { UNA }\end{array}$ & $-3,431,767$ & 1,786 & 3,907 & 0.5885 & 37 \\
\hline
\end{tabular}

Table 8. Comparison of airline's Shapley values and daily flights.

\begin{tabular}{c|c|c|c|c}
\multirow{2}{*}{ Scenario } & \multicolumn{2}{|c|}{ Shapley Values } & \multicolumn{2}{c}{ Daily Flights } \\
\cline { 2 - 5 } Airlines & Before & After & Before & After \\
\hline \multirow{2}{*}{ FAT } & $\$ 12,440$ & $\$ 72,330$ & $5(\mathrm{MD}-83)$ & $5(\mathrm{MD}-83)$ \\
& & $12(\mathrm{~B} 757)$ & $3(\mathrm{~B} 757)$ \\
TNA & $\$ 2,920$ & $\$ 8,450$ & 5 & 3 \\
UNA & $\$ 17,240$ & $\$ 127,770$ & 15 & 8 \\
MDA & $\$ 18,570$ & $\$ 129,450$ & 16 & 8 \\
Total & $\$ 51,170$ & $\$ 338,000$ & 53 & 27 \\
\hline
\end{tabular}

As for the distribution of profits among airlines, Table 8 shows the solutions derived from the application of Shapley values and the information provided from Tables 6 and 7 . From Table 8, we learn that airlines with higher flight frequency and lower operating costs would be more competitive than their partners with lower flight frequency and higher operating cost. For example, airlines such as MDA and UNA are much more powerful in bargaining games. As a result, they would gain more profits than their partners.

\section{CONCLUSION}

The All in all, we summarize our contributions as follows:

- Given the solution approach, we provides useful insights for the decision markers in the market to set up their optimal fare rates and frequency that yield maximum profits for all carriers under the assumption of efficiency and market equilibrium.

- By integrating modal choices in our model, we could evaluate the impacts of THSR on other intercity modes of transport under competition environment. In addition, by taking account of the modal interactions into our framework, we are able to propose new price regulations under new service frequency based on social welfare.

- We formulate our objective functions as a maximization problem of social welfare to determine the upper bounds of fare rate restriction. And we apply Nash equilibrium to evaluate the impacts of THSR's operation on the other competing modes and solve their optimal fare rates in the system of maximization problems of their profits. We also show that the optimal fare rates solved by the maximization of carrier's profit function would be bounded by the upper bound solved by the maximization of social welfare. These upper bounds should be used as guidance for policy makers of the transport authority in their fare rate regulation practices because they are calculated base on new market equilibrium. And most importantly, the adoption of these new calculation rules regarding prices and service frequency can be justified by the greater good of our society.

- We learn that the operations of THSR may have significant impacts on railway and freeway buses. Yet, the impacts of THSR on railway and freeway buses have not fully revealed until the first quarter of 2008 when THSR increases its service frequency to more than 100 daily trains and provides free shuttle bus services. On the other hand, more than half of the daily revenue passengers from airlines have been transferred to THSR in the first year of operations as predicted by our model. We believe that the impacts of THSR on railway and freeway buses could also be predicted by the use of our model.

Additional findings in our case study are summarized as below:

- The estimated model parameters are consistent with our $a$ priori assumption, i.e., market shares decrease as fare rates increase, and shorter headways lead to higher utility.

- The estimated payoffs for various coalitions support the super-additive property in the cooperative games. Nevertheless, the results are consistent with our a priori, i.e., the optimal airfares would increase as the market concentration ratio rises.

- By applying Shapley value to solve the payoff distribution among airlines, we find that airlines with more daily flights and lower operating costs would be more competitive and more powerful in bargaining with their partners. In other words, they would suffer less loss or gain more profits than their partners.

- Both airlines and freeway may have room for raising their 
CAL's Daily Profit Function

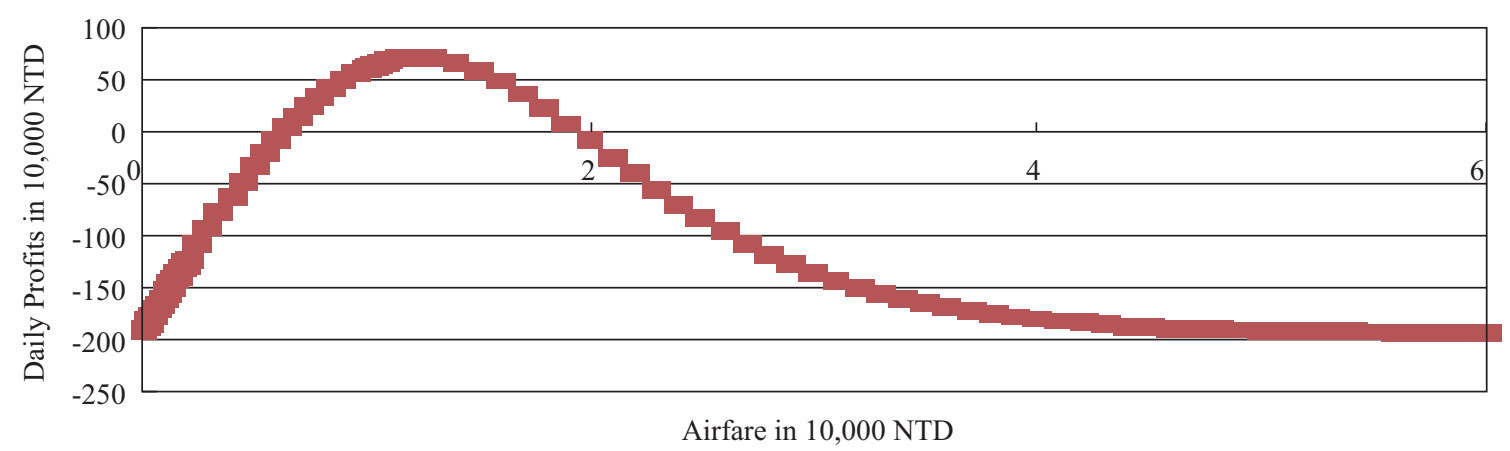

Fig. 2. Estimated China Airline's daily profit function of passenger flights - Taipei to San Francisco in 2001.

fare rates to increase revenues because THSR could operate at 23 trains per day in the first year, only one third of the fully capacity in the future, and the fare of THSR is $16 \%$ higher than the rate announced in 2006. However, to maintain profitability, airlines would have to unify as an alliance and cut their daily flights by $50 \%$. Since the services provided by airlines could be easily replaced by THSR as predicted by our model, the future of airlines in the domestic market would rely on the mercy of THSR. In other words, if THSR continue to increase its service frequency and lower its promotion prices, then the chances for airlines to be able to compete with THSR are very slim.

Meanwhile, we have the following suggestions for future research directions:

- A comprehensive survey of the cost data for major competing modes in domestic markets, especially THSR and railways, and the cost reduction due to alliances, are required for a better presentation of payoff functions.

- Strategic planning regarding the scheduling problems should be integrated into our model. Empirical studies suggest that travelers care about the schedule no less than fare rates in choosing their modes of travel. Therefore, a more comprehensive framework should include the scheduling plans for all competing modes.

- A before-and-after analysis regarding the travel demand of THSR should be examined in the near future to validate all the predictions made by previous works. By comparing the predicted and the revealed patronages, we can learn the lessons from the good and the bad predictions. Eventually, these lessons will help us to remedy all the mistakes in future demand modeling.

\section{APPENDIX}

The profit functions in the forms of (13) and (14) have similar shapes as shown in Fig. 2, which was reported in the case study presented by Shyr and Chang [9]. Based on the shape of the profit function, clearly it has a unique solution.

\section{REFERENCES}

1. Ben-Akiva, M. and Lerman S., Discrete Choice Analysis, MIT Press, Cambridge, Massachusetts (1985).

2. Button, K., "Does the theory of the 'core' explain why airlines fail to cover their long-run costs of capital?" Journal of Air Transport Management, Vol. 9, Issue 1, PP. 5-14 (2003).

3. Curiel, I., Cooperative Game Theory and Applications, Kluwer Academic Press, Boston (1997).

4. Hansen, M., "Airline competition in a hub-dominated environment: an application of non-cooperative game theory," Transportation Research B, Vol. 24B, No. 1, pp. 27-43 (1990).

5. Lin, J. J., Feng, C. M., and Huang L. C., "Forecasting the Taiwan High Speed Rail System on Local Development," Transportation Planning Journal (Taiwan), Vol. 34, No. 3, pp. 391-412 (2005).

6. Ministry of Transportation and Communications, A Report on the Survey of High Speed Rail Travel Behavior, Taipei, Taiwan (2007).

7. Morikawa, T., Incorporating Stated Preference Data in Travel Demand Analysis, MIT doctoral dissertation, Cambridge, Massachusetts (1989).

8. Owen, G., Game Theory - $2^{\text {nd }}$ edition, Academic Press Inc., Orlando, Florida (1982).

9. Shyr, O. F. and Chang, L., "An effectiveness assessment of code-sharing practices among airlines: a cooperative game approach," Transportation Planning Journal, Vol. 32, No. 4, pp. 601-630 (2003).

10. Shyr, O. F. and Kuo, Y., "Applying TOPSIS and cooperative game theory in airline coalition decisions," Journal of Marine Science and Technology-Taiwan, Vol. 16, No. 1, pp. 8-18 (2008).

11. Shyr, O. F. and Shieh, C., "Applying game theory on strategic planning of freeway buses in competing with high speed rail," Transportation Planning Journal, Vol. 38, No. 1, pp. 69-83 (2009).

12. Varian, H., Economic and Financial Modeling with MATHEMATICA, Springer-Verlag Publishers, the Electronic Library of Science, Santa Clara, California (1993). 